\title{
Synthesis of CdS nanostructures using Schiff base complexes
}

\author{
Ranjana Sharma ${ }^{1}$, Y C Goswami ${ }^{2}$, Rajeev Singh ${ }^{1}$ and D Kumar ${ }^{3 *}$ \\ ${ }^{1}$ Deptt. of Chemistry \& Environmental Sc., ITM-GOI, Sithouli, Gwalior-474001, India \\ ${ }^{2}$ School of Physical Sciences, ITM University, Turari, Gwalior-474001, India \\ ${ }^{3}$ Centre of Research for Chemical Sciences, Post Graduate Department of Chemistry, \\ SMS Govt Model Science College, Jiwaji University, Gwalior-474001, India \\ *Email: drdkumar65@gmail.com
}

CdS nanoparticles were synthesized using the cadmium complex of dithiocarbazate schiff base in dimethyl sulfoxide (DMSO) at different temperatures by using new microwave assisted chemical route. Dithiocarbazate schiff base, in turn, was formed by the condensation of Sbenzyl dithio carbazate with acetophenone. The as-prepared nanocomposite possesses excellent optical properties.

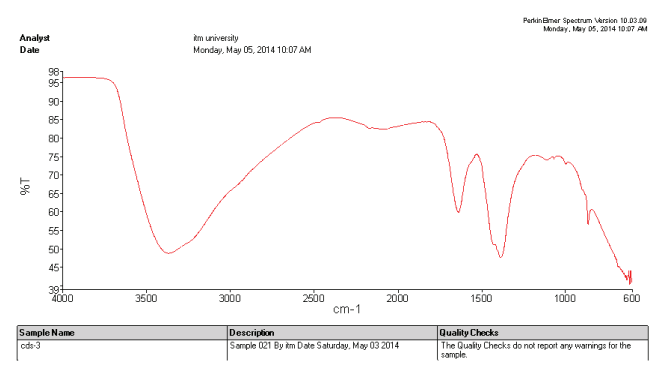

Figure 1: FTIR Spectrum for CdS nanoparticles

The structure and morphology of the asprepared Cadmium Sulphide nanoparticles were studied by X-ray diffraction (XRD), transmission electron microscopy (TEM), UVVIS studies and photoluminescence studies. An FTIR spectrum (Figure 1) shows peaks for $\mathrm{Cd}$ $\mathrm{S}$ bonds.

All the XRD peaks are identified for CdS. Close to spherical shaped particles were observed in the TEM images of all samples shown in Figure 2. The optical properties of the particles studied by UV-VIS and photoluminescence (PL) spectroscopy showed evidence of quantum confinement. The particles show strong luminescence in the visible region, make them suitable for various optoelectronic applications.

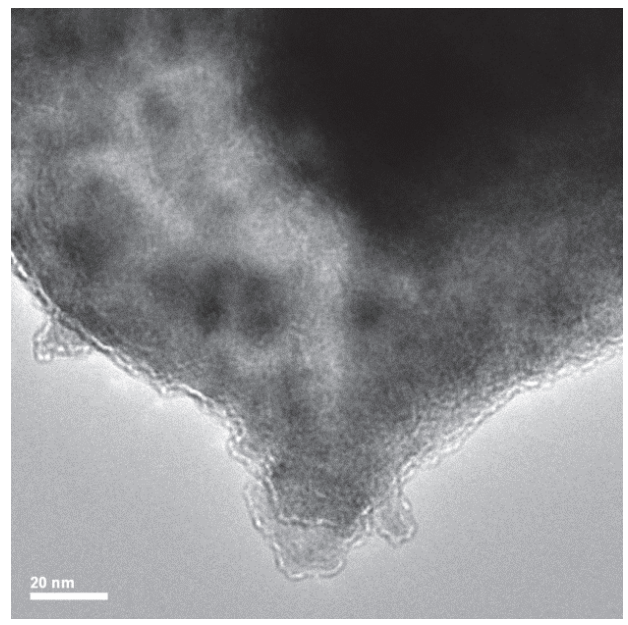

Figure 2: TEM micrograph of CdS nanoparticles

Keywords: CdS, dithiocarbazate complex, nanoparticles

\section{References}

1.Maryam Shakouri-Arani and Masoud Salavati-Niasari, New J Chem. 38 ( 2014) 1179-1185.

2. D Ayodhya, M Venkatesham, A S Kumari, G B Reddy , D Ramakrishna, G Veerabhadram, J Fluoresc. 25(5) (2015) 148192. 